\title{
RESPONSABILIDADE AMBIENTAL DAS EMPRESAS DE MINERAÇÃO E SUAS OBRIGAÇÕES EM FACE DA POLÍTICA NACIONAL DE SEGURANÇA DE BARRAGENS
}

\section{ENVIRONMENTAL RESPONSIBILITY FOR MINING COMPANIES AND THEIR OBLIGATIONS IN RESPECT OF THE NATIONAL POLICY OF DAM SAFETY}

\section{RENATA MARQUES FERREIRA}

Pós-Doutora pela Universidade de São Paulo (Escola Politécnica-USP) e Doutora em Direito das Relações Sociais (sub área de Direitos Difusos e Coletivos-Direito Ambiental) pela Pontifícia Universidade Católica de São Paulo. Mestre em Direito das Relações Sociais (sub área de Direitos Difusos e Coletivos-Direito Ambiental Tributário) pela Pontifícia Universidade Católica de São Paulo. Professora convidada da Escola Superior de Advocacia da Ordem dos Advogados do Brasil - Seção de São Paulo (ESA-OAB/SP).

\section{CELSO ANTONIO PACHECO FIORILLO}

Doutor e Mestre em Direito das Relações Sociais. Director Académico do Congresso de Derecho Ambiental Contemporáneo España/Brasil-Universidade de Salamanca(ESPANHA) e Miembro del Grupo de Estudios Procesales de la Universidad de Salamanca-Grupo Investigación ReconocidoIUDICIUM(ESPANHA).Professor convidado visitante da Escola Superior de Tecnologia do Instituto Politécnico de Tomar(PORTUGAL) e Professor Visitante/Pesquisador da Facoltà di Giurisprudenza della Seconda Università Degli Studi di Napoli(ITALIA).Professor Permanente do Programa de Mestrado em Direito da UNINOVE-SP(BRASIL). Professor convidado do Curso de Especialização em Engenharia Sanitária Ambiental da Universidade Mackenzie.Professor da Escola Superior da Magistratura Federal do RS.Elaborador/coordenador/professor do Curso 
de Pós Graduação em Direito Ambiental da Escola Paulista da MagistraturaEPM.Professor MBA Direito Empresarial /FUNDACE-USP.

\section{RESUMO}

Objetivo: O objetivo da pesquisa está focado em interpretar a aplicação do ordenamento infraconstitucional definidido no âmbito da Lei no. 12.344/2010, em face da necessária obediência ao preconizado pelo direito ambiental constitucional e seus princípios, em especial com destaque para a gestão de risco de atividades econômicas subordinadas aos princípios ambientais constitucionais da prevençãoprecaução e do poluidor pagador.

Metodologia: Foi utilizado o método hermenêutico, por meio do levantamento dos trabalhos doutrinários elaborados por especialistas que atuam no âmbito da matéria investigada e análise jurídica afeita ao direito ambiental constitucional, bem como das normas infraconstitucionais.

Resultados: Concluiu-se que os empreendedores são responsáveis pela existência de crimes ambientais, sendo certo que as empresas de mineração submetem-se ao previsto no art. 225, §3‥ da Constituição de 1988 e, no plano infraconstitucional, fazse um especial destaque ao previsto na Lei no. 9.605/1998. Demonstrou-se, ainda, a real necessidade de uma referência especial aos princípios da prevenção e da precaução, independentemente da obediência às obrigações normativas estabelecidas no complexo de normas elencadas neste estudo.

Contribuições: Para evitar tragédias que vêm ocorrendo no Brasil, em face das atividades econômicas desenvolvidas licitamente por empresas que atuam em vários seguimentos, em foco o setor de mineração, é imperioso interpretar a aplicação do ordenamento infraconstitucional definido pela Lei no. 12.334/2010, em face da obediência ao que determina o direito ambiental constitucional e seus princípios.

PALAVRAS-CHAVE: Empresas de mineração; Política Nacional de Segurança de Barragens; princípios ambientais constitucionais da prevenção, da precaução e do poluidor pagador; responsabilidade ambiental constitucional.

\section{ABSTRACT}

Objective: The objective of the research is focused on interpreting the application of the infra-constitutional order defined by Law No. 12,344/2010, in view of the necessary compliance with the provisions of constitutional environmental law and its 
principles, in particular the risk management of economic activities subordinated to the constitutional environmental principles of prevention and precaution as well as the polluter payer.

Methodology: The hermeneutic method was used, by surveying the doctrinal works elaborated by specialists acting in the investigated subject area and legal analysis related to the constitutional environmental law, as well as the infraconstitutional norms.

Results: It was concluded that the entrepreneurs are responsible for the existence of environmental crimes, being certain that the mining companies are submitted to the provisions of art. 225, par. 3, Constitution of 1988, and in the infra-constitutional sphere, a special emphasis is given to the provisions of Law No. 9,605/1998. The real need for a special reference to the principles of prevention and precaution has been demonstrated, regardless of the compliance with the normative obligations established in the complex of norms listed in this study.

Contributions: In order to avoid tragedies that are occurring in Brazil due to the economic activities lawfully developed by companies operating in various segments, focusing on the mining sector, it is imperative to interpret the application of the infraconstitutional order defined by Law No. 12,334/2010, in view of the obedience to what determines the constitutional environmental law and its principles.

KEYWORDS: Mining Companies; National Dam Safety Policy; constitutional environmental principles of prevention, precaution and polluter payer; constitutional environmental liability.

\section{INTRODUÇÃO}

O rompimento da barragem de rejeitos da empresa de mineração Samarco, maior desastre do gênero da história mundial nos últimos 100 anos ocorrido em novembro de 2015 em Mariana (MG) bem como o recente acidente vinculado à barragem da empresa Vale, segunda maior mineradora do mundo ,ocorrido em janeiro de 2019 em Brumadinho, na região metropolitana de Belo Horizonte (MG), demonstra a necessidade de se observar no plano jurídico, de forma clara e objetiva, os deveres dos empreendedores que atuam em referido segmento em face do que estabelece a Política Nacional de Segurança de Barragens (Lei 12.334/10) dentro de contexto constitucional mais amplo que vincula os princípios gerais da atividade econômica em face do princípio da defesa do meio ambiente (Art.170,VI) 
Destarte, para objetivamente se evitar as tragédias que vem ocorrendo em nosso País em face das atividades econômicas desenvolvidas por referidas empresas, é imperioso analisar a aplicação da lei 12.334/10 em face das superiores normas ambientais constitucionais, a saber, em face de necessária obediência ao que determina o direito ambiental constitucional bem como às obrigações estabelecidas em referido complexo de normas.

Referida análise será desenvolvida no presente artigo, estruturado através de pesquisa realizada a partir do método hermenêutico, por meio do levantamento dos trabalhos doutrinários elaborados por estudiosos especializados atuantes no âmbito da matéria investigada e da análise jurídica vinculada ao direito ambiental constitucional assim como das normas infraconstitucionais tudo com o objetivo de adequar de forma satisfatória o enquadramento do tema em face de nosso sistema jurídico em vigor.

\section{OS EMPREENDEDORES EM FACE DA POLÍTICA NACIONAL DE SEGURANÇA DE BARRAGENS (LEI 12.334/10)}

Estabelecida para balizar juridicamente as barragens destinadas à acumulação de água para quaisquer usos, à disposição final ou temporária de rejeitos (barragem de rejeito, como ensina Herbert Rafael [MATURANO RAFAEL, 2012] é uma estrutura de terra construída para armazenar resíduos de mineração) e à acumulação de resíduos industriais que apresentem pelo menos uma das características definidas pelo legislador (Art.1ํㅡㄹ incisos I a IV da lei 12.334/10), a Política Nacional de Segurança de Barragens define empreendedor como o agente privado ou governamental com direito real sobre as terras onde se localizam a barragem e o reservatório ou que explore a barragem para benefício próprio ou da coletividade (art. $2^{\circ}$, IV da lei 12.334/10).

Em face de referida norma jurídica os empreendedores são os responsáveis legais pela segurança da barragem (sabendo-se que a segurança de uma barragem influi diretamente na sua sustentabilidade e no alcance de seus potenciais efeitos 
sociais e ambientais como estabelece o art.4ํ, $\mathrm{V}$ da lei 12.334/10) cabendo-lhes o desenvolvimento de ações para garanti-la (art.4ํ. III) particularmente em face dos fundamentos estabelecidos pelo Art. $4^{\circ}$ da aludida Política. Daí, as obrigações definidas pela lei indicadas no Art.17, como, dentre outras, a de prover os recursos necessários à garantia da segurança da barragem (Art.17, I) a de organizar e manter em bom estado de conservação as informações e a documentação referentes ao projeto, à construção, à operação, à manutenção, à segurança e, quando couber, à desativação da barragem(Art.17,III) bem como a de permitir o acesso irrestrito do órgão fiscalizador e dos órgãos integrantes do Sindec ao local da barragem e à sua documentação de segurança(Art.17,VI) sendo certo que a barragem que não atender aos requisitos de segurança nos termos da legislação pertinente deverá ser recuperada ou desativada pelo seu empreendedor, que deverá comunicar ao órgão fiscalizador as providências adotadas(Art.18).

De qualquer forma, claro está que, explorando a barragem em benefício próprio no sentido de desenvolver lucrativa atividade econômica em seu proveito(o Brasil é considerado o segundo maior produtor de minério de ferro do mundo e o maior exportador dessa matéria-prima para a China ${ }^{1}$ sendo certo que a empresa Vale $S / A$ apresentou lucro recorrente de $R \$ 8,3$ bilhões e distribuiu dividendos da ordem de US $\$ 1,142$ bilhão, apenas no terceiro trimestre de $2018^{2}$ ), os empreendedores do segmento antes referido, além de submetidos às regras infraconstitucionais definidas na Política Nacional de Segurança de Barragens, subordinam-se no plano constitucional,particularmente, às superiores normas jurídicas balizadoras de nossa ordem econômica.

Vejamos.

\footnotetext{
${ }^{1}$ http://www.mme.gov.br acesso em 26 de janeiro de 2019.

2http://vale.com/PT/investors/informationmarket/quartelyresults/ResultadosTrimestrais/vale IFRs BRL 3T18p.pdf acesso em 26 de janeiro de 2019.
} 


\section{OS EMPREENDEDORES QUE EXPLORAM BARRAGENS EM BENEFÍCIO PRÓPRIO NO SENTIDO DE DESENVOLVER ATIVIDADE ECONÔMICA E SUA TUTELA JURÍDICA CONSTITUCIONAL: PRINCÍPIOS GERAIS DA ATIVIDADE ECONÔMICA E A DEFESA DO MEIO AMBIENTE}

Ao assegurar a todos o livre exercício de qualquer atividade econômica, independentemente de autorização de órgãos públicos, salvo nos casos previstos em lei,(parágrafo único do art. 170 da CF) nossa Constituição Federal destacou de forma importante a necessidade de se interpretar no plano normativo o significado de referido conceito de atividade em face de seus evidentes reflexos em toda a ordem econômica constitucional particularmente em decorrência do direcionamento estabelecido pelos próprios princípios gerais da atividade econômica (TÍTULO VII Da Ordem Econômica e Financeira - CAPÍTULO I - DOS PRINCÍPIOS GERAIS DA ATIVIDADE ECONÔMICA).

Não se trata evidentemente de pura e simplesmente compreender a atividade em face tão somente da economia, a saber, dentro do termo economia, lembrando Antonio Dias Leite (LEITE, 2011),como o "quadro físico e institucional dentro do qual se realizam as atividades de produção de bens e serviços requeridos pela sociedade, bem como sua evolução no tempo" mas de compreender de que forma "as atividades de produção de bens e serviços requeridos pela sociedade" tem seu balizamento fixado pela Constituição Federal.

Trata-se a rigor, como lembram Celso Fiorillo e Renata Ferreira (FIORILLO e FERREIRA,2018), de verificar o que significa atividade no contexto econômico normativo constitucional lembrando, de forma evidentemente menos ampla, dentro de análise doutrinária jurídica e em contexto infraconstitucional, ser a atividade "conceito básico de direito comercial, fenômeno essencialmente humano (Bonfante, Lezioni di storia del commercio). E hoje se pode afirmar que é conceito básico de direito empresarial. A empresa se realiza pela atividade, como o sujeito se realiza por seus atos. Tanto $o$ ato quanto a atividade se exteriorizam por meio de negócios jurídicos, de tal sorte que se afirma que o contrato é o núcleo básico da atividade empresarial (Bulgarelli, Contratos mercantis,p.25)". 


\section{Com efeito.}

Entendida, na lição de Houaiss (HOUAISS, 2009), como "qualidade; faculdade ou possibilidade de agir, de se mover, de fazer, empreender coisas; exercício dessa faculdade, ação " em face do que se admite ser ativo ("que exerce ação, que age, que tem a faculdade de agir") o termo atividade também pode ser perfeitamente explicado no âmbito da economia(atividade econômica) como a faculdade de empreender coisas o que facilita evidentemente seu entendimento no contexto da ordem econômica constitucional com evidentes reflexos no direito ambiental constitucional, ou seja, a livre iniciativa passa a atuar em absoluta sintonia com os princípios fundamentais do direito ambiental constitucional.

Assim, como já teve oportunidade de estabelecer o Supremo Tribunal Federal, "é certo que a ordem econômica na Constituição de 1988 define opção por um sistema no qual joga um papel primordial a livre iniciativa. Essa circunstância não legitima, no entanto, a assertiva de que o Estado só intervirá na economia em situações excepcionais"3.

\footnotetext{
3 "EMENTA: AÇÃO DIRETA DE INCONSTITUCIONALIDADE. LEI N. 7.844/92, DO ESTADO DE SÃO PAULO. MEIA ENTRADA ASSEGURADA AOS ESTUDANTES REGULARMENTE MATRICULADOS EM ESTABELECIMENTOS DE ENSINO. INGRESSO EM CASAS DE DIVERSÃO, ESPORTE, CULTURA E LAZER. COMPETÊNCIA CONCORRENTE ENTRE A UNIÃO, ESTADOS-MEMBROS E O DISTRITO FEDERAL PARA LEGISLAR SOBRE DIREITO ECONÔMICO. CONSTITUCIONALIDADE. LIVRE INICIATIVA E ORDEM ECONÔMICA. MERCADO.

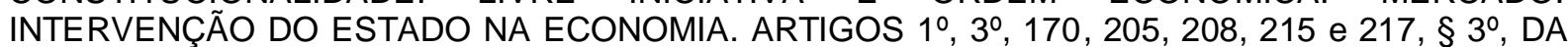
CONSTITUIÇÃO DO BRASIL. 1. É certo que a ordem econômica na Constituição de 1.988 define opção por um sistema no qual joga um papel primordial a livre iniciativa. Essa circunstância não legitima, no entanto, a assertiva de que o Estado só intervirá na economia em situações excepcionais. 2. Mais do que simples instrumento de governo, a nossa Constituição enuncia diretrizes, programas e fins a serem realizados pelo Estado e pela sociedade. Postula um plano de ação global normativo para o Estado e para a sociedade, informado pelos preceitos veiculados pelos seus artigos $1 \stackrel{0}{ }, 3^{\circ}$ e 170. 3. A livre iniciativa é expressão de liberdade titulada não apenas pela empresa, mas também pelo trabalho. Por isso a Constituição, ao contemplá-la, cogita também da "iniciativa do Estado"; não a privilegia, portanto, como bem pertinente apenas à empresa. 4. Se de um lado a Constituição assegura a livre iniciativa, de outro determina ao Estado a adoção de todas as providências tendentes a garantir o efetivo exercício do direito à educação, à cultura e ao desporto [artigos 23, inciso V, 205, 208, 215 e $217 \S 3^{\circ}$, da Constituição]. Na composição entre esses princípios e regras há de ser preservado o interesse da coletividade, interesse público primário. 5. 0 direito ao acesso à cultura, ao esporte e ao lazer, são meios de complementar a formação dos estudantes. 6. Ação direta de inconstitucionalidade julgada improcedente."

ADI 1950 / SP - SÃO PAULO AÇÃO DIRETA DE INCONSTITUCIONALIDADE Relator:Min. EROS GRAU Julgamento: 03/11/2005 Órgão Julgador: Tribunal Pleno Publicação DJ 02-06-2006 PP00004 EMENT VOL-02235-01 PP-00052 LEXSTF v. 28, n. 331, 2006, p. 56-72 RT v. 95, n. 852, 2006, p. 146-153.
} 
Destarte, no plano superior constitucional em vigor (princípio fundamental), a livre iniciativa (Art. $1^{\circ}$, IV da CF) como "princípio do liberalismo econômico que defende a total liberdade do indivíduo para escolher e orientar sua ação econômica, independentemente da ação de grupos sociais ou do Estado" implicando em "total garantia da propriedade privada, o direito de o empresário investir seu capital no ramo que considerar mais favorável e fabricar e distribuir os bens produzidos em sua empresa da forma que achar mais conveniente à realização dos lucros", conforme explicação de Paulo Sandroni(SANDRONI, 2005), deixa de ser observada em face de sua interpretação histórica inicial e passa a ser admitida em contexto contemporaneo de evidente equilíbrio.

Daí a existência de princípios ambientais constitucionais como os observados nos incisos do Art.170 sendo certo que dentre os referidos princípios, está exatamente o da defesa do meio ambiente natural/recursos ambientais, do meio ambiente cultural/cidades, do meio ambiente artificial/cidades e do meio ambiente do trabalho/saúde ambiental (Art.170, VI da CF), cujo conteúdo constitucional está descrito no Art.225 da CF, inclusive mediante tratamento diferenciado conforme o impacto ambiental (Art.225, parágrafo $1^{\circ}, \mathrm{IV}$ ) dos produtos e serviços e de seus processos de elaboração e prestação.

Por via de consequência ao assegurar a todos o livre exercício de qualquer atividade econômica, inclusive evidentemente aquelas das empresas de mineração que exploram barragens em benefício próprio, nossa Constituição Federal condiciona no plano normativo o exercício de referida atividade econômica não só à defesa do meio ambiente natural/recursos ambientais orientada necessariamente pelos princípios do direito ambiental constitucional, (dentre outros, pelos princípios da prevenção, precaução, poluidor-pagador, etc.) na forma de suas respectivas tutelas jurídicas constitucionais como submete as empresas/empreendedores que exploram barragens em benefício próprio às obrigações ambientais derivadas de aludidos comandos normativos conforme a objetiva e segura orientação estabelecida pelo Supremo Tribunal Federal na conhecida ADI $3540^{4}$.

4"A ATIVIDADE ECONÔMICA NÃO PODE SER EXERCIDA EM DESARMONIA COM OS PRINCÍPIOS DESTINADOS A TORNAR EFETIVA A PROTEÇÃO AO MEIO AMBIENTE. - A 


\title{
4 A OBRIGAÇÃo IMPOSTA PELA CONSTITUIÇÃo FEDERAL AO EMPREENDEDOR DE DEFENDER E PRESERVAR, EM BENEFÍ́CIO DAS PRESENTES E FUTURAS GERAÇÕES, O DIREITO AMBIENTAL: OS DEVERES AMBIENTAIS EM FACE DAS ATIVIDADES ECONÔMICAS
}

\author{
Conforme interpretado pelo Supremo Tribunal Federal (ADI 3540),
} incumbe, ao Estado e à própria coletividade, a especial obrigação de defender e preservar, em benefício das presentes e futuras gerações, o direito ambiental, a saber, as relações jurídicas vinculadas ao meio ambiente natural, ao meio ambiente cultural, ao meio ambiente artificial (espaço urbano) e ao meio ambiente laboral submetem-se à obrigação constitucional antes referida.

O adimplemento de referido encargo, que é irrenunciável na interpretação estabelecida pelo STF, representa a garantia de que não se instaurarão, no seio da coletividade, os graves conflitos intergeneracionais marcados pelo desrespeito ao dever de solidariedade, que a todos se impõe, na proteção desse direito.

Destarte,a atividade econômica balizada em nossa Constituição Federal), está condicionado não só, evidentemente, ao que determinam os princípios fundamentais constitucionais(Arts. $1^{\circ}$ a $4^{\circ}$ da CF),como particularmente às superiores obrigações fixadas diretamente a partir do que determinam os referidos arts.225 e 170, VI da Constituição Federal dentro de uma perspectiva mais ampla destinada a fundamentar a gênese da obrigação ambiental no plano da denominada relação jurídica ambiental (Art.225 da CF).

Resta, portanto bem evidenciado que as atividades desenvolvidas no plano da ordem econômica estabelecidas em nossa Constituição Federal, principalmente aquelas vinculadas a explorar barragens em benefício próprio no sentido de

incolumidade do meio ambiente não pode ser comprometida por interesses empresariais nem ficar dependente de motivações de índole meramente econômica, ainda mais se se tiver presente que a atividade econômica, considerada a disciplina constitucional que a rege, está subordinada, dentre outros princípios gerais, àquele que privilegia a "defesa do meio ambiente" (CF, art. 170, VI), que traduz conceito amplo e abrangente das noções de meio ambiente natural, de meio ambiente cultural, de meio ambiente artificial (espaço urbano) e de meio ambiente laboral. Doutrina". ADI 3540 MC / DF - DISTRITO FEDERAL MEDIDA CAUTELAR NA ACCÃO DIRETA DE INCONSTITUCIONALIDADE Relator: Min. CELSO DE MELLO Julgamento: 01/09/2005 Órgão Julgador: Tribunal Pleno Publicação DJ 03-02-2006 PP-00014 EMENT VOL-02219-03 PP-00528. 
desenvolver lucrativa atividade econômica, estão condicionadas às obrigações fixadas pela Lei Maior, ou seja, para se estabelecer a exata dimensão das obrigações ambientais necessitamos ter clareza que, no plano constitucional, as obrigações ambientais estão vinculadas não só aos recursos ambientais, mas, como adverte Celso Fiorillo (FIORILLO, 2019) "igualmente a bens ambientais outros também abarcados pela relação jurídica ambiental" ou seja, ao direito ambiental constitucional.

Passemos, pois a uma breve análise da causa geradora das obrigações ambientais.

5 CAUSA GERADORA DAS OBRIGAÇÕES AMBIENTAIS (OBRIGAÇÕES DO EMPREENDEDOR) E SUA EXEGESE NO PLANO CONSTITUCIONAL: ESPECIFICIDADES DE ATIVIDADES ECONÔMICAS GERADORAS DE NECESSIDADE DE ARMAZENAMENTO DE RESÍDUOS DE MINERAÇÃO E AS OBRIGAÇÕES DE FAZER OU NÃO FAZER SUBORDINADAS AOS PRINCÍPIOS AMBIENTAIS CONSTITUCIONAIS DA PREVENÇÃO, PRECAUÇÃO E DO POLUIDOR PAGADOR

A obrigação, como estabelecia Carvalho Santos (CARVALHO SANTOS,1953) em analise do tema no plano infraconstitucional e com amparo na lição de Polacco (POLACCO,Obbligazioni,n.1) "é relação jurídica patrimonial em virtude da qual o devedor é vinculado a uma prestação de índole positiva, ou negativa para com o credor. Consiste, por conseguinte, a substancia das obrigações em ser alguém constrangido a dar, fazer ou prestar alguma coisa". Sendo em regra "apreciáveis economicamente" e "redutíveis a uma soma em dinheiro", como advertia Beviláqua (BEVILÁQUA,1954), se submetem evidentemente à ordem econômica constitucional em vigor(Art.1 ${ }^{\circ}$, IV c/c Art.170 e segs da CF).

Ao esclarecer, também em plano infraconstitucional, as causas geradoras das obrigações, já advertia Beviláqua (BEVILÁQUA,1954) que as fontes das obrigações (o contrato, o chamado quase contrato, atos ilícitos e vontade unilateral) 
"admitiriam ainda uma simplificação, se as reduzíssemos a duas:o ato humano e a lei, elementos que se não devem dissociar de modo completo, porque o ato humano desprovido de sanção legal é juridicamente improfícuo e, por outro lado, a lei exige a insuflução vital da atividade humana, para descer do mundo abstrato, onde paira e rutila, sem o que não conseguirá realizar o fim a que se destina".

Assim, fundamentada diretamente no texto de nossa Lei Maior (Art.225, parágrafos $1^{\circ}$ a $7^{\circ}$ e especificamente Arts. $225, \S 1^{\circ}$,IV e $225, \S 3^{\circ}$ da CF) e em face de balizamento que guarda necessariamente harmonia com os princípios gerais da atividade econômica (Art.170, VI), a causa geradora das obrigações ambientais, como destacam Celso Fiorillo e Renata Ferreira(FIORILLO e FERREIRA,2019), "está explicita e diretamente relacionada à tutela jurídica constitucional do meio ambiente em face das quatro noções de meio ambiente indicadas pela interpretação do Supremo Tribunal Federal: as obrigações ambientais vinculadas à tutela jurídica do meio ambiente natural(recursos ambientais como bens ambientais tutelados pelo Art.225 da (F), as obrigações ambientais vinculadas à tutela jurídica do meio ambiente cultural(bens culturais como bens ambientais tutelados pelos arts.215/216 da Constituição Federal), as obrigações ambientais vinculadas à tutela jurídica do meio ambiente artificial(a cidade como bem ambiental tutelada pelos arts. $182 \mathrm{~s} 183$ da CF) e as obrigações ambientais vinculadas à tutela jurídica do meio ambiente do trabalho(a saúde como bem ambiental tutelada pelos arts.196 a 200 da CF)". Além disso, e no que se refere às especificidades de atividades econômicas geradoras de necessidade de armazenamento de resíduos de mineração, estabelece nossa Carta Magna que aquele que explorar recursos minerais fica obrigado a recuperar o meio ambiente degradado(meio ambiente natural/recursos ambientais, meio ambiente cultural, meio ambiente artificial e meio ambiente do trabalho/saúde ambiental), de acordo com solução técnica exigida pelo órgão público competente, na forma da lei (Art.225, $\S 2^{\circ}$ ) e evidentemente em face de interpretação constitucional já estabelecida pelo Supremo Tribunal Federal(ADI 3540).

Destarte, podendo ser entendida teoricamente a partir da lição Beviláqua (BEVILÁQUA, 1954) como "a relação transitória de direito, que nos constrange a dar, fazer ou não fazer alguma coisa, em regra economicamente apreciável, em 
proveito de alguém que, por ato nosso ou de alguém conosco juridicamente relacionado, ou em virtude de lei, adquiriu o direito de exigir de nós essa ação ou omissão", a obrigação ambiental, em face de sua gênese constitucional, visa "constranger" o Estado e à própria coletividade(inclusive evidentemente e particularmente aqueles que atuam desenvolvendo atividades econômicas), a rigorosamente obedecer as superiores balizas normativas no que se refere ao uso dos bens ambientais (recursos ambientais, bens culturais, cidades e saúde). Tratase, portanto de obrigação constitucional via de regra estabelecida num fazer ou não fazer dentro de princípios constitucionais que subordinam o uso dos bens ambientais assegurados em nossa ordem econômica à defesa do meio ambiente (Art.170, VI da CF).

Daí, e sempre em obediência aos mandamentos constitucionais, a aplicação, dentre outros, dos denominados princípios da prevenção, precaução e do poluidor-pagador no que se refere à interpretação e efetividade das obrigações ambientais e, portanto às obrigações ambientais das empresas de mineração geradoras de necessidade de armazenamento de resíduos.

\section{OBRIGAÇÕES AMBIENTAIS DO EMPREENDEDOR EM FACE DO PRINCÍPIO DA PREVENÇÃO: AS OBRIGAÇÕES PREVENTIVAS E O ESTUDO PRÉVIO DE IMPACTO AMBIENTAL (EPIA)}

Em face da superior orientação constitucional, num primeiro momento, e como regra, impõe-se ao obrigado (empreendedor) o dever de arcar com as despesas de prevenção dos danos ao meio ambiente que a sua atividade possa ocasionar (meio ambiente natural, meio ambiente cultural, meio ambiente artificial e meio ambiente do trabalho).

Daí, inclusive, a incumbência constitucional estabelecida ao Poder Público visando exigir, na forma da lei, para instalação de obra ou atividade potencialmente causadora de significativa degradação do meio ambiente, estudo prévio de impacto ambiental, a que se dará publicidade (EPIA - Art. Art. 225, § 1ํ, IV). 
Notamos, portanto que nossa Constituição Federal, visando dar efetividade ao princípio da prevenção, criou um inédito instrumento destinado a fixar obrigação preventiva àqueles que pretendem instalar obra ou mesmo atividade potencialmente causadora de significativa degradação ao meio ambiente (meio ambiente natural, meio ambiente cultural, meio ambiente artificial e meio ambiente do trabalho) gerando por via de consequência um constante e necessário processo de controle das atividades econômicas a partir do licenciamento ambiental, como "ato administrativo pelo qual o órgão ambiental competente, estabelece as condições, restrições e medidas de controle ambiental que deverão ser obedecidas pelo empreendedor, pessoa física ou jurídica, para localizar, instalar, ampliar e operar empreendimentos ou atividades utilizadoras dos recursos ambientais consideradas efetiva ou potencialmente poluidoras ou aquelas que, sob qualquer forma, possam causar degradação ambiental"' como indicam Celso Fiorillo, Paulo Ferreira e Dione Morita(FIORILLO,FERREIRA e MORITA,2019), assim como no plano infraconstitucional, como é o caso específico da Política Nacional de Segurança de Barragens, o estabelecimento de regras objetivas de fiscalização e controle permanente das atividades econômicas desenvolvidas pelo empreendedor conforme indicado pelos arts.9\%(inspeções de segurança regular e especial) , 10(revisão periódica de segurança de barragem) e 12(ações a serem executadas pelo empreendedor da barragem em caso de situação de emergência) da lei 12.334/10.

Destarte, as referidas obrigações de índole preventiva, por força constitucional e em obediência aos critérios específicos infraconstitucionais, serão via de regra sempre exigíveis daqueles que atuam na ordem econômica capitalista, e evidentemente das empresas geradoras de necessidade de armazenamento de resíduos de mineração. 


\title{
6.1 AS EMPRESAS GERADORAS DE NECESSIDADE DE ARMAZENAMENTO DE RESÍDUOS DE MINERAÇÃO EM FACE DAS ATIVIDADES POTENCIALMENTE CAUSADORAS DE SIGNIFICATIVA DEGRADAÇÃO DO MEIO AMBIENTE: O ESTUDO PRÉVIO DE IMPACTO AMBIENTAL (ART.225, PARÁGRAFO 1丷, IV), O PRINCÍPIO DA PRECAUÇÃO E A GESTÃO DE RISCO NO ÂMBITO DA POLITICA NACIONAL DE SEGURANÇA DE BARRAGENS
}

Instrumento normativo originário do ordenamento jurídico americano, tomado de empréstimo por outros países, como a Alemanha, a França e, por evidência, o Brasil, "de gênese e natureza jurídica constitucional e visando assegurar efetividade na tutela jurídica constitucional dos bens ambientais", como destacam Fiorillo, Fereira e Morita(FIORILLO,FERREIRA e MORITA,2019), o Estudo Prévio de Impacto Ambiental, como instrumento preventivo estrutural, passou a ser exigido pela Lei Maior de 1988 na forma do que determina o Art.225, § 1丷, IV, a saber:

\begin{abstract}
Art. 225. Todos têm direito ao meio ambiente ecologicamente equilibrado, bem de uso comum do povo e essencial à sadia qualidade de vida, impondo-se ao Poder Público e à coletividade o dever de defendê-lo e preservá-lo para as presentes e futuras gerações. $\S 1^{\circ}$ Para assegurar a efetividade desse direito, incumbe ao Poder Público: IV - exigir, na forma da lei, para instalação de obra ou atividade potencialmente causadora de significativa degradação do meio ambiente, estudo prévio de impacto ambiental, a que se dará publicidade.
\end{abstract}

Assim, para assegurar a efetividade da tutela jurídica dos bens ambientais em face das varias relações jurídicas ambientais disciplinadas em nossa Carta Magna(Patrimônio Genético, Meio Ambiental Cultural, Meio Ambiente Digital, Meio Ambiente Artificial/Cidades, Saúde Ambiental/Meio Ambiente do Trabalho e Meio Ambiente Natural) entendeu por bem nossa Constituição Federal determinar obrigatória incumbência ao Poder Público no sentido de exigir do mesmo, na forma da lei, para atividade potencialmente causadora de significativa degradação do meio ambiente ,como é o caso evidente das empresas de mineração,o referido estudo de impacto que deve ser sempre e necessariamente prévio e público. 
Destarte, em nosso País, as diferentes atividades previstas em nosso ordenamento jurídico que potencialmente ,"suscetível de existir ou acontecer" na lição de Houaiss(HOUAISS,2009), possam causar significativa degradação do meio ambiente, a saber, atividades que possam causar "alteração adversa das características do meio ambiente" (Art.3ํ, II da lei 6938/81) necessitam apresentar referido estudo no sentido de obedecer aos princípios e normas constitucionais anteriormente indicadas.

As empresas geradoras de necessidade de armazenamento de resíduos de mineração, portanto, devem observar o referido comando constitucional.

Claro está que a referida alteração adversa, para restar cabalmente caraterizada, dependerá de cada caso concreto, a saber, dependerá da real situação a ser examinada (Patrimônio Genético, Meio Ambiental Cultural, Meio Ambiente Digital, Meio Ambiente Artificial/Cidades, Saúde Ambiental/Meio Ambiente do Trabalho e Meio Ambiente Natural) assim como deverá ser devidamente avaliada em decorrência de conhecimento técnico especializado, verdadeiro trabalho elaborado por perito conforme clássica lição de Chiovenda (CHIOVENDA,2000), a saber," pessoas chamadas a expor ao juiz não só as observações de seus sentidos e suas impressões pessoais sobre os fatos observados, senão também as induções que se devam tirar objetivamente dos fatos observados ou que thes dêem por existentes. Isto faz supor que eles são dotados de certos conhecimentos técnicos ou aptidões em domínios especiais, tais que não devam estar ao alcance, ou no mesmo grau, de qualquer pessoa culta".

De qualquer forma as atividades potencialmente causadoras de significativa degradação do meio ambiente geram a exigência constitucional de estudo prévio de impacto ambiental, a que se dará a necessária publicidade sendo certo que a partir do RE 627.189 o Poder Público, como adverte Celso Fiorillo (FIORILLO, 2019) "em face da incumbência que lhe foi determinada pelo art. 225, § 10, IV, deverá analisar os riscos, avaliar os custos das medidas de prevenção e, ao final, executar as ações necessárias, as quais serão decorrentes de "decisões universais, não discriminatórias, motivadas, coerentes e proporcionais", como procedimento de 
gestão de riscos obrigatório nas atividades econômicas vinculadas ao meio ambiente natural/recursos naturais.

Cuida-se, portanto de obedecer a um critério de gestão de risco em acatamento ao denominado princípio da precaução conforme interpretação realizada pelo Supremo Tribunal Federal em $2016^{5}$.

Daí também, no âmbito do plano específico da Política Nacional de Segurança de Barragens, a definição de gestão de risco, como " ações de caráter normativo, bem como aplicação de medidas para prevenção, controle e mitigação de riscos"(Art.2 $2^{\circ}, \mathrm{VI}$ da lei 12.334/10) dentro do objetivo de fomentar a cultura de segurança de barragens e gestão de riscos previstos no Art. $3^{\circ}, \mathrm{VII}$ da aludida Política.

Trata-se, por via de consequência, de análise qualitativa e quantitativa, que evidentemente não se reveste de caráter absoluto, a ser aplicada sempre que

5 "EMENTA Recurso extraordinário. Repercussão geral reconhecida. Direito Constitucional e Ambiental. Acórdão do tribunal de origem que, além de impor normativa alienígena, desprezou norma técnica mundialmente aceita. Conteúdo jurídico do princípio da precaução. Ausência, por ora, de fundamentos fáticos ou jurídicos a obrigar as concessionárias de energia elétrica a reduzir o campo eletromagnético das linhas de transmissão de energia elétrica abaixo do patamar legal. Presunção de constitucionalidade não elidida. Recurso provido. Ações civis públicas julgadas improcedentes. 1. 0 assunto corresponde ao Tema no 479 da Gestão por Temas da Repercussão Geral do portal do STF na internet e trata, à luz dos arts. 5o, caput e inciso II, e 225, da Constituição Federal, da possibilidade, ou não, de se impor a concessionária de serviço público de distribuição de energia elétrica, por observância ao princípio da precaução, a obrigação de reduzir o campo eletromagnético de suas linhas de transmissão, de acordo com padrões internacionais de segurança, em face de eventuais efeitos nocivos à saúde da população. 2. O princípio da precaução é um critério de gestão de risco a ser aplicado sempre que existirem incertezas científicas sobre a possibilidade de um produto, evento ou serviço desequilibrar o meio ambiente ou atingir a saúde dos cidadãos, o que exige que o estado analise os riscos, avalie os custos das medidas de prevenção e, ao final, execute as ações necessárias, as quais serão decorrentes de decisões universais, não discriminatórias, motivadas, coerentes e proporcionais. 3. Não há vedação para o controle jurisdicional das políticas públicas sobre a aplicação do princípio da precaução, desde que a decisão judicial não se afaste da análise formal dos limites desses parâmetros e que privilegie a opção democrática das escolhas discricionárias feitas pelo legislador e pela Administração Pública. 4. Por ora, não existem fundamentos fáticos ou jurídicos a obrigar as concessionárias de energia elétrica a reduzir o campo eletromagnético das linhas de transmissão de energia elétrica abaixo do patamar legal fixado. 5. Por força da repercussão geral, é fixada a seguinte tese: no atual estágio do conhecimento científico, que indica ser incerta a existência de efeitos nocivos da exposição ocupacional e da população em geral a campos elétricos, magnéticos e eletromagnéticos gerados por sistemas de energia elétrica, não existem impedimentos, por ora, a que sejam adotados os parâmetros propostos pela Organização Mundial de Saúde, conforme estabelece a Lei no 11.934/2009. 6. Recurso extraordinário provido para - fim de julgar improcedentes ambas as ações civis públicas, sem a fixação de verbas de sucumbência." RE 627189 / SP - SÃO PAULO RECURSO EXTRAORDINÁRIO Relator: Min. DIAS TOFFOLI Julgamento: 08/06/2016 Órgão Julgador: Tribunal Pleno Publicação ACÓRDÃO ELETRÔNICO REPERCUSSÃO GERAL - MÉRITO DJe-066 DIVULG 31-03-2017 PUBLIC 03-042017 
existirem incertezas científicas sobre a possibilidade de um produto, evento ou serviço desequilibrar o meio ambiente ou atingir a saúde dos cidadãos, tudo com a finalidade de balizar as atividades econômicas- incluindo evidentemente as empresas ora mencionadas- exercidas em harmonia com os princípios destinados a tornar efetiva a proteção ao meio ambiente.

\subsection{A OBRIGAÇÃO CONSTITUCIONAL DE REPARAR DANOS CAUSADOS AO MEIO AMBIENTE:OBRIGAÇÕES AMBIENTAIS DOS EMPREENDEDORES EM FACE DO PRINCÍPIO DO POLUIDOR PAGADOR}

Podemos identificar no princípio do poluidor - pagador duas órbitas de alcance: a) busca evitar a ocorrência de danos ambientais (caráter preventivo); e b) ocorrido o dano, visa à sua reparação (caráter repressivo).

Desse modo e conforme destacam Celso Fiorillo e Renata Ferreira (FIORILLO e FERREIRA, 2018) "num primeiro momento, impõe-se ao poluidor, na condição de obrigado, o dever de arcar com as despesas de prevenção dos danos ao meio ambiente que a sua atividade possa ocasionar. Cabe a ele, além da elaboração do necessário EPIA, o ônus de utilizar instrumentos necessários à prevenção dos danos".

Numa segunda órbita de alcance, esclarece este princípio que, ocorrendo danos ao meio ambiente em razão da atividade desenvolvida, o poluidor será responsável pela sua reparação, ou seja, e conforme advertência do Ministro Marco Aurélio na ADI 3378 "o fato verificado, o dano, porque não se pode cogitar de indenização, a priori, sem a verificação de dano". A obrigatoriedade de reparar o dano está, pois em conformidade com o princípio de direito ambiental constitucional do poluidor-pagador.

A definição do princípio foi dada pela Comunidade Econômica Europeia, que preceitua: 
pelos padrões ou medidas equivalentes que assegurem a qualidade de vida, inclusive os fixados pelo Poder Público competente" (ver Diretivas da União Europeia).

Na Constituição Federal de 1988, encontramos o princípio previsto no art. $225, \S 3$ ㅇ:

$\S 3$ o As condutas e atividades consideradas lesivas ao meio ambiente sujeitarão os infratores, pessoas físicas ou jurídicas, a sanções penais e administrativas, independentemente da obrigação de reparar os danos causados.

Vale observar que na órbita repressiva do princípio do poluidor-pagador há incidência da denominada "responsabilidade civil" porquanto o próprio pagamento resultante da poluição não possui caráter de pena, nem de sujeição à infração administrativa, o que, por evidente, não exclui a cumulatividade destas, como prevê a Constituição Federal no referido § 3 o do art. 225.

Com isso, é correto afirmar que o princípio do poluidor-pagador determina a incidência e aplicação de alguns aspectos do regime jurídico da impropriamente denominada "responsabilidade civil" em face dos danos ambientais, a saber: a) a prioridade da reparação específica do dano ambiental; b) a denominada responsabilidade chamada civil objetiva; e c) solidariedade para suportar os danos causados ao meio ambiente.

6.2.1 A prioridade da reparação específica do dano ambiental: retorno ao statu quo ante como critério balizador do uso dos bens ambientais

Dano, na clássica definição estabelecida por Fischer (FISCHER,1938), é "todo o prejuízo que o sujeito de direitos sofra através da violação dos seus bens jurídicos" advertindo que "na verdade, dentro do direito positivo o dano só interessa enquanto facto que condiciona a aplicação duma pena ou a constituição dum dever de indemnizar como consequências jurídicas".

Com efeito.

O ressarcimento do dano ambiental vinculado ao inadequado uso dos bens 
ambientais pode ser feito de duas formas. A primeira delas ocorre com o que se denomina reparação natural ou específica, em que há o ressarcimento "in natura". A segunda, como sublinha Fischer (FISCHER,1938) "é a indenização em dinheiro".

Todavia, isso não significa que a reparação pode, indiferentemente, ser feita por um modo ou outro. Pelo contrário, primeiramente, deve-se verificar se é possível o retorno ao statu quo ante por via da específica reparação, e só depois de infrutífera tal possibilidade é que deve recair a condenação sobre um quantum pecuniário, até mesmo porque, na lembrança de Wambier (WAMBIER, 1998) por vezes, "é difícil a determinação do quantum a ser ressarcido pelo causador do ato feito, sendo sempre preferível a reparação natural, pela recomposição efetiva e direta do ambiente prejudicado". De fato, como lembra Fischer (FISCHER,1938) "o sistema de reparação natural é evidentemente muito mais adequado para atingir o fim ideal de "restaurar", sendo indiferentemente aplicável aos danos patrimoniais e não patrimoniais, que muitas vezes se confundem entre as consequências dum mesmo acto".

Assim o adequado uso dos bens ambientais com vistas à sua utilização racional e disponibilidade permanente em face de superior orientação constitucional (Art.170, VI c/c Art.225 da CF) orienta a prevalência da reparação in natura influenciando necessariamente todas as normas infraconstitucionais ambientais.

Daí, na lição clássica contida na obra de Enneccerus (ENNECCERUS, 1954) "la compensación de los daños puede hacerse restableciendo efetivamente el estado que existiria de no haberse producido el acontecimento causa del daño(reposicion natural § 249 C.c) o, de manera imperfecta, sólo com dinero a tenor del valor(prestación del interés pecuniário)".

6.2.2 A denominada responsabilidade chamada "civil" objetiva e a obrigação constitucional dos empreendedores de reparar danos causados ao meio ambiente

Como observado anteriormente, nossa Carta Magna (Art.225, § $3^{\circ}$ ) em face de condutas e atividades consideradas lesivas ao meio ambiente (meio ambiente natural, meio ambiente cultural, meio ambiente artificial e meio ambiente do trabalho) 
sujeita os infratores, pessoas físicas ou jurídicas, na clara manifestação de Celso Fiorillo (FIORILLO. 2018) "a obrigação de reparar danos causados dentro evidentemente das hipóteses, observando-se caso a caso, previstas em nossa Lei Maior conforme temos aduzido em nossas obras".

Destarte o uso de bens ambientais (os recursos ambientais, os bens culturais, as cidades e a saúde), em desacordo com as superiores orientações do direito ambiental constitucional, submetem os obrigados a reparar o dano causado, tendo em vista, na sempre lembrada lição do Ministro Celso de Mello (ADI 3540) "a especial obrigação de defender e preservar, em benefício das presentes e futuras gerações, esse direito de titularidade coletiva e de caráter transindividual".

Trata-se, pois de responsabilidade fixada por nossa Constituição Federal (e não tão somente por regras infraconstitucionais...), em face de ordem econômica capitalista e dos riscos dela derivados (Art.1ํ, IV c/c Art.170 e segs), que visa assegurar a reparação do dano entendido, na lição clássica contida na obra de Enneccerus (ENNECCERUS,1954) como "toda desventaja que experimentamos em nuestros bienes jurídicos(patrimônio, cuerpo, vida, salud, honor, crédito, bienestar, capacidade de adquisición, etc)" .Daí, ao estabelecer comando destinado ao dever de reparar danos causados ao meio ambiente, ter nossa Lei Maior cuidado também da "manera imperfecta, sólo com dinero a tenor del valor(prestación del interés pecuniário)".

Aqui, evidentemente, não estabeleceu nossa Constituição Federal uma regra de "reponsabilidade civil" fundamentada em tradicional lição lembrada por Guido Alpa (ALPA, 2010) e estruturada na clássica teoria da responsabilidade contratual sob o fundamento da culpa e seus requisitos essenciais como ensinava Alvino Lima (LIMA,1998),a saber, uma regra jurídica associada à doutrina que fundamenta historicamente o subsistema normativo civil vinculado à ideologia de um "direito privado" ou mesmo de quaisquer outras regras estabelecidas a partir de interpretação emanada diretamente de leis federais.

$\mathrm{Na}$ verdade cuidou nossa Carta Magna, isto sim, de deixar explicitada de forma clara e inequívoca comando destinado a reparar danos causados em virtude de condutas e atividades consideradas lesivas ao meio ambiente realizada por 
infratores (pessoas físicas ou jurídicas) dentro de interpretação própria de gênese constitucional, ou seja, e lembrando a clássica lição de Alvino Lima (LIMA, 1998) citando Josserand(JOSSERAND, 1926), "quem guarda os benefícios que o acaso de sua atividade the proporciona deve, inversamente, suportar os males decorrentes da mesma atividade".

Por via de consequência e visando estabelecer o uso dos bens ambientais em harmonia com a defesa do meio ambiente dentro de hipóteses de responsabilidade em que não importaria, na adequada interpretação de Celso Fiorillo (FIORILLO, 2019) "[...] em nenhum julgamento de valor sobre os atos do responsável" bastando" que o dano se relacione materialmente com estes atos, porque aquele que exerce uma atividade deve assumir os riscos", nossa Constituição Federal está assentada "na equação binária cujos polos são o dano e a autoria do evento danoso".

Assim determina nossa Constituição Federal, diretamente e independentemente de critérios outros fixados em normas infraconstitucionais (Art.225, $\S 3^{\circ}$ ), que as condutas e atividades consideradas lesivas ao meio ambiente sujeitarão os infratores, pessoas físicas ou jurídicas, a obrigação de reparar os danos causados. Trata-se de dever de reparação em que é irrelevante o dolo ou culpa dos infratores (responsabilidade objetiva) exigindo-se, todavia, necessariamente, além da existência do dano a existência do nexo de causalidade entre o fato e o dano, a saber, "sólo se há de indemnizar aquel daño que constituya uma consecuencia del hecho que obliga a la indemnización" na precisa advertência de Enneccerus (ENNECCERUS,1954).

6.2.3 A denominada conjunção solidária constitucional: a solidariedade para suportar os danos causados ao meio ambiente

Tendo sua estrutura jurídica fixada diretamente no texto de nossa Carta Magna interpretada a partir dos princípios fundamentais constitucionais (Art.1ํ a IV da CF) e estabelecida em face da defesa do meio ambiente como princípio geral da atividade econômica (Art.170 Vl), conforme amplamente desenvolvido 
anteriormente, as obrigações ambientais estão constitucionalmente ligadas aos deveres indicados no Art.225 da Constituição Federal impostos ao Poder Público e à coletividade.

\author{
Daí, exatamente no sentido de compatibilizar a ordem econômica \\ constitucional (Art.170 e segs da CF) com os deveres estabelecidos pela cláusula \\ constitucional proclamadora do direito fundamental ao meio ambiente (Art.225 da \\ $\mathrm{CF})^{6}$, interpretado particularmente pelo que estabelece o Art.3ํㅡ, I de nossa Lei Maior, \\ a existência, no plano das obrigações ambientais, da denominada solidariedade
}

\begin{abstract}
6 "Direta e necessariamente extraídos da cláusula constitucional do direito à saúde tomada como princípio, somente podem ser afirmados, sem necessidade de intermediação política, os conteúdos desde já decididos pelo Poder Constituinte: aquilo que o Poder Constituinte, representante primário do povo soberano, textualmente decidiu retirar da esfera de avaliação e arbítrio do Poder Legislativo, representante secundário do povo soberano. Adotar essa postura frente às cláusulas constitucionais fundamentais não significa outra coisa senão levar a sério os direitos, como bem lembra o renomado professor da Escola de Direito da Universidade de Nova lorque, Jeremy Waldron: "Nós discordamos sobre direitos e é compreensível que seja assim. Não deveríamo s temer nem ter vergonha de tal desacordo, nem abafá-lo e empurrá-lo para longe dos fóruns nos quais importantes decisões de princípios são tomadas em nossa sociedade. Nós devemos acolhê-lo. Tal desacordo é um sinal - o melhor sinal possível em circunstâncias modernas - de que as pessoas levam os direitos a sério. Evidentemente, (...) uma pessoa que se encontra em desacordo com outras não é por essa razão desqualificada de considerar sua própria visão como correta. Nós devemos, cada um de nós, manter a fé nas nossas próprias convicções. Mas levar os direitos a sério é também uma questão de como responder à oposição de outros, até mesmo em uma questão de direitos. (...) Levar os direitos a sério, então, é responder respeitosamente a esse aspecto de alteridade e então estar disposto a participar vigorosamente - mas como um igual - na determinação de como devemos viver juntos nas circunstâncias e na sociedade que compartilhamos." Esse mesmo cuidado deve ser adotado pela Corte no que se refere à cláusula constitucional proclamadora do direito fundamental ao meio ambiente ecologicamente equilibrado como essencial à sadia qualidade de vida (art. 225), sobre a qual registro a análise minuciosa de Celso Antônio Pacheco Fiorillo, para quem a Constituição da República conclui pela presença de quatro concepções fundamentais no âmbito do direito ambiental: a) de que todos têm direito ao meio ambiente ecologicamente equilibrado; b) de que o direito ao meio ambiente ecologicamente equilibrado diz respeito à existência de um bem de uso comum do povo e essencial à sadia qualidade de vida, criando em nosso ordenamento o bem ambiental; c) de que a Carta Magna determina tanto ao Poder Público como à coletiv idade o dever de defender o bem ambiental, assim como o dever de preservá-lo; d) de que a defesa e a preservação do bem ambiental estão vinculadas não só às presentes como também às futuras gerações.(grifos nossos) A Constituição Federal de 1988, ao incluir entre seus princípios fundamentais a dignidade da pessoa

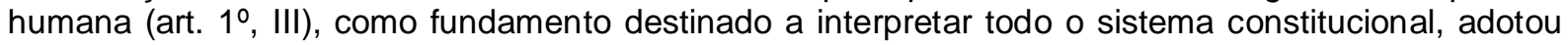
visão explicitamente antropocêntrica, que reflete em toda a legislação infraconstitucional - o que abarca também a legislação ambiental.(grifos nossos) O Constituinte originário atribuiu aos brasileiros e estrangeiros residentes no País (arts. 12, I, e 52 da Carta Magna) posição de centralidade em relação ao nosso sistema de direito positivo. Nesse sentido o Princípio n. 1 da Declaração do Rio de Janeiro sobre Meio Ambiente e Desenvolvimento de 1992: "Os seres humanos estão no centro das preocupações com o desenvolvimento sustentável. Têm direito a uma vida saudável e produtiva, e m harmonia com a natureza". ADI 4066 / DF - DISTRITO FEDERAL AÇÃO DIRETA DE INCONSTITUCIONALIDADE Relatora: Min. ROSA WEBER Julgamento: 24/08/2017 Órgão Julgador: Tribunal Pleno Publicação PROCESSO ELETRÔNICO DJe-043 DIVULG 06-03-2018 PUBLIC 07-03-2018
\end{abstract}


passiva.Trata-se de analisar a matéria, como ensinava Bevilaqua em face de análise infraconstitucional (BEVILÁQUA,1954) no âmbito da denominada conjunção solidária, a saber "o credor poderá pedir o cumprimento da obrigação a qualquer dos condevedores, sem que este possa alegar o benefício da divisão. Se, porem, preferir, tem a faculdade de fazer valer o seu direito a todos simultaneamente, abrangendo-os, sob o mesmo golpe de ação. Permite-se-lhe ainda escolher, apalpar a força de resistência dos devedores, Demandando um que não se mostre em boas condições de satisfaze - lo plenamente, por debilidade patrimonial, Ihe é lícito recuar, voltando-se para outro, a ver se oferece mais solidez".

A referida solidariedade, estabelecida como dissemos no plano constitucional, visa assegurar o adimplemento da obrigação ambiental por parte de qualquer dos obrigados admitindo-se, todavia a faculdade de fazer valer a obrigação a todos simultaneamente.

Constatada, pois a denominada conjunção solidária constitucional determinada pelo Art.225(Poder Público e coletividade) tem o obrigado, depois de haver satisfeito a obrigação ambiental "o direito de exigir, de cada um de seus consócios na dívida, sua parte respectiva, distribuindo-se igualmente, por todos os porção insolúvel, que porventura restar" conforme ensinava Beviláqua (BEVILAQUA, 1954).

\subsection{CONDUTAS E ATIVIDADES CONSIDERADAS LESIVAS AO MEIO AMBIENTE SUJEITANDO OS INFRATORES, PESSOAS FÍSICAS OU JURÍDICAS, A SANÇÕES PENAIS: A RESPONSABILIDADE AMBIENTAL CRIMINAL DOS EMPREENDEDORES (ART. 225, § 3o, DA CF)}

Observados os critérios indicados no direito penal constitucional em vigor entendeu por bem nossa Carta Magna sujeitar qualquer infrator, seja ele pessoa física seja ele pessoa jurídica, às sanções penais ambientais, "desde que observada a existência de crime ambiental" conforme adverte Celso Fiorillo (FIORILLO,2017).

Com efeito. 
O STF acabou adotando a interpretação de referido autor em $2013^{7}$ ao reconhecer a possibilidade de se processar penalmente uma pessoa jurídica, através de didática lição da Ministra Rosa Weber ao advertir que o STJ estaria violando diretamente a Constituição Federal, ao deixar de aplicar um comando expresso, previsto no artigo 225, parágrafo $3^{\circ}$, segundo o qual as condutas lesivas ao meio ambiente sujeitam as pessoas físicas e jurídicas a sanções penais e administrativas afastando pois o entendimento de referida Corte segundo o qual a persecução penal de pessoas jurídicas só seria possível se estiver caracterizada ação humana individual.

Assim além das obrigações e responsabilidades antes referidas, os empreendedores são responsáveis em face da existência de crime ambiental sendo certo que as empresas de mineração, evidentemente, se submetem ao que determina o Art.225, § 3ㄴ, da CF bem como, no plano infraconstitucional, ao que estabelece a lei $9605 / 98$.

\section{CONCLUSÃO}

Os deveres dos empreendedores/empresas de mineração vinculados ao que estabelece a Política Nacional de Segurança de Barragens (Lei 12.334/10), principalmente em face da exploração de barragem para benefício de suas atividades empresariais, devem ser necessariamente interpretados dentro de contexto constitucional mais amplo que vincula os princípios gerais da atividade econômica em face do princípio da defesa do meio ambiente (Art.170,VI). Assim, para que objetivamente possamos evitar as tragédias que vem ocorrendo em nosso País em face das atividades econômicas desenvolvidas licitamente por empresas que atuam em segmentos como o de mineração, é imperioso interpretar a aplicação do ordenamento infraconstitucional definido no âmbito da lei 12.334/10 em face de necessária obediência ao que determina o direito ambiental constitucional e seus princípios, com destaque para os princípios da prevenção e da precaução,

\footnotetext{
${ }^{7}$ STF, RE 548.181 AgR/PR, $1^{\text {a }}$ T., Min. Rosa Weber, j. em 14-5-2013
} 
independentemente da obediência às obrigações normativas estabelecidas em referido complexo de normas.

\section{REFERÊNCIAS}

ALPA, Guido La responsabilità civile. Parte generale Utet Giuridica,2010.

ART, Henry W. Dicionário de ecologia e ciência ambiental. São Paulo: Companhia Melhoramentos, 1998.

BEVILAQUA, Clovis. Direito das Obrigações. $8^{\text {a }}$ edição Rio de Janeiro: Livraria Francisco Alves,1954.

CARVALHO SANTOS, J.M. Código Civil Brasileiro Interpretado Parte Geral (arts.863-927) Volume IX 6를 edição Rio de Janeiro: Livraria Freitas Bastos, 1953.

ENNECCERUS, Ludwig. Derecho de Obligaciones. Barcelona: Bosch Casa Editorial,1954.

FIORILLO, Celso Antonio Pacheco. Curso de Direito Ambiental Brasileiro. 19 edição, revista, ampliada e atualizada São Paulo: Saraiva, 2019.

. Crimes Ambientais. 2ª edição, São Paulo: Saraiva, 2017.

Direito Processual Ambiental Brasileiro - A defesa judicial do patrimônio genético, do meio ambiente cultural, do meio ambiente digital, do meio ambiente artificial, do meio ambiente do trabalho e do meio ambiente natural no Brasil. $7^{\text {a }}$ edição. , São Paulo: Saraiva, 2018.

; FERREIRA, Paulo; MORITA, Dione Mari. Licenciamento Ambiental. $3^{\text {a }}$ edição, São Paulo: Saraiva, 2019.

; FERREIRA, Renata Marques. Direito ambiental tributário. 4" edição, São Paulo: Saraiva, 2018.

O agronegócio em face do direito ambiental constitucional brasileiro: as empresas rurais sustentáveis Rio de Janeiro: Lumen Juris, 2018.

Segurança alimentar e desenvolvimento sustentável: a tutela jurídica da alimentação e das empresas alimentares em face do direito ambiental brasileiro. Rio de Janeiro: Lumen Juris, 2019

FISCHER, Hans Albrecht. A reparação dos danos no direito civil. Coimbra: Armeio Amado Editor, 1938. 
HOUAISS, Antonio. Dicionário Houaiss da Língua Portuguesa. Rio de Janeiro,2009,1ª edição, Objetiva.

. Dicionário Houaiss da Língua Portuguesa. $1^{\text {a }}$ Edição Rio de Janeiro: Objetiva, 2009.

JOSSERAND, Louis. Les Transports En Service Intérieur et En Service International Rousseau, 1926.

LEITE, Antonio Dias. A Economia Brasileira - de onde viemos e onde estamos. Rio de Janeiro: Elsevier, 2011.

LIMA, Alvino. Culpa e Risco. $2^{\underline{a}}$ edição São Paulo: Editora dos Tribunais, 1998.

MATURANO RAFAEL, Herbert Miguel. Angel Análise do Potencial de Liquefação de uma Barragem de Rejeito. Dissertação (Mestrado em Engenharia Civil)Pontifícia Universidade Católica do Rio de Janeiro, Rio de Janeiro, 2012.

POLACCO, Vittorio. Le obbligazioni nel diritto civile italiano. Imprenta: Roma, Athenaeum, 1915.

SANDRONI, Paulo Sandroni. Dicionário de Economia do Século XXI. Rio de Janeiro/São Paulo, Editora Record, 2005.

WAMBIER, Luis Rodrigues. Liquidação do dano. São Paulo, Revista dos Tribunais, 1998. 